\title{
Phylogenomic analysis of polyketide synthase-encoding genes in Trichoderma
}

\section{Correspondence \\ Scott E. Baker \\ scott.baker@pnnl.gov}

Received 21 July 2011

Revised 29 September 2011

Accepted 11 November 2011
Scott E. Baker, ${ }^{1}$ Giancarlo Perrone, ${ }^{2}$ Nathan M. Richardson, ${ }^{3}$

Antonia Gallo ${ }^{2}$ and Christian P. Kubicek ${ }^{4}$

\author{
${ }^{1}$ Chemical and Biological Process Development Group, Pacific Northwest National Laboratory, \\ Richland, WA, USA \\ ${ }^{2}$ Institute of Sciences of Food Production (ISPA), National Research Council (CNR), Bari, Italy \\ ${ }^{3}$ Washington State University, Tri-Cities, Richland, WA, USA \\ ${ }^{4}$ Area Biotechnology and Microbiology, Institute of Chemical Engineering, \\ Vienna University of Technology, Vienna, Austria
}

\begin{abstract}
Members of the economically important ascomycete genus Trichoderma are ubiquitously distributed around the world. The mycoparasitic lifestyle and plant defence-inducing interactions of Trichoderma spp. make them ideal biocontrol agents. Of the Trichoderma enzymes that produce secondary metabolites, some of which likely play important roles in biocontrol processes, polyketide synthase (PKSs) have garnered less attention than non-ribosomal peptide synthetases such as those that produce peptaibols. We have taken a phylogenomic approach to study the PKS repertoire encoded in the genomes of Trichoderma reesei, Trichoderma atroviride and Trichoderma virens. Our analysis lays a foundation for future research related to PKSs within the genus Trichoderma and in other filamentous fungi.
\end{abstract}

\section{INTRODUCTION}

Given its important roles in bioenergy-related enzyme production and plant and fungal health, the genus Trichoderma has a significant economic footprint (Schuster \& Schmoll, 2010). This genus is well known for its opportunistic lifestyle that includes saprotrophy, mycoparasitism, endophytism, and interactions with plants and animals. Because of their ability to antagonize other fungi and stimulate plant defences against phytopathogens, Trichoderma strains have become prominent biocontrol agents (Schuster \& Schmoll, 2010). Further highlighting their mycoparasitic lifestyle, sequencing and analysis of the genomes from two mycoparasitic Trichoderma species (Trichoderma virens, Trichoderma atroviride) have shown that these genomes encode a rich catalogue of fungal cell wall-degrading chitinases and a relative paucity of plant cell wall-degrading enzymes (Kubicek et al., 2011; Martinez et al., 2008).

As biocontrol agents and pathogens of fungal food crops, secondary metabolite production in Trichoderma spp. is of

Abbreviations: CAI, codon adaptation index; HGT, horizontal gene transfer; KS domain, ketosynthase domain; MP analysis, maximumparsimony analysis; MSAS, 6-methylsalicylic acid synthase; PKS, polyketide synthase.

Five supplementary figures and two supplementary tables are available with the online version of this paper. particular importance. Trichoderma and other filamentous fungi are well known for the production of a diverse array of secondary metabolites. Non-ribosomal peptides and polyketides comprise a major portion of these products, which are synthesized by large proteins composed of various domains for the individual enzymic steps (Cox, 2007). Both broad and genus-specific phylogenomic and functional analysis of polyketide synthase (PKS)- and non-ribosomal peptide synthetase (NRPS)-encoding genes have been performed, which has accelerated the pace at which genes and pathways are being linked to specific secondary metabolites (Bushley \& Turgeon, 2010; Bushley et al., 2008; Chiang et al., 2010; Cramer et al., 2006; Gaffoor et al., 2005; Kroken et al., 2003; Kubicek et al., 2011; Lee et al., 2005).

Trichoderma spp. are probably best known for their production of peptaibols, which are non-ribosomal peptides with antimicrobial and plant defence-stimulating activity (Viterbo et al., 2007). Relatively less studied in Trichoderma are PKSs. The recent analysis of the three available Trichoderma genome sequences has indicated that the genomes of these organisms encode only a small catalogue of PKSs: T. atroviride and T. virens each encode 18, and Trichoderma reesei only 11 predicted PKSs (Kubicek et al., 2011; Martinez et al., 2008). We have manually annotated and performed phylogenomic analysis of the catalogue of Trichoderma PKSs. 


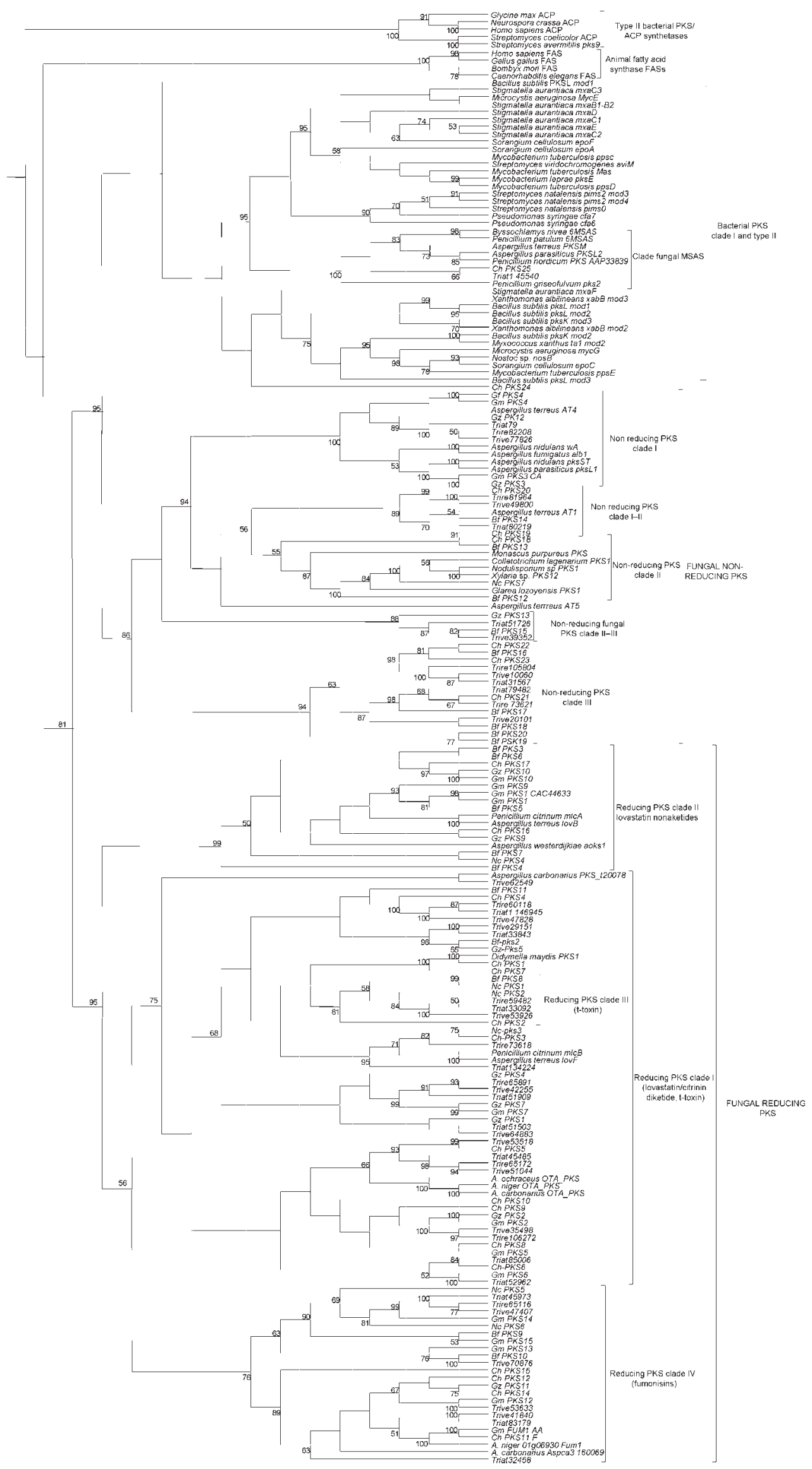


Fig. 1. Genealogy of Trichoderma PKSs, inferred by MP analysis of the KS domain. Major clades and subclades are indicated by vertical bars, each of which shares a common organization of domains (those in parentheses are variable in their presence/ absence within that clade). Numbers above branches indicate percentage bootstrap support for each clade (numbers below $50 \%$ are not shown). Abbreviations: $\mathrm{Bf}=$ Botrytinia fuckeliana, $\mathrm{Gm}=$ Gibberella moniliformis, $\mathrm{Gz}=\mathrm{Gibberella} \mathrm{zeae,}$ $\mathrm{Nc}=$ Neurospora crassa, $\mathrm{Ch}=$ Cochliobolus heterostrophus. The accession numbers for all sequences obtained from GenBank are given by Kroken et al. (2003).

\section{METHODS}

\begin{abstract}
Phylogenetic analysis. The amino acid sequences of the ketosynthase (KS) domains were aligned using CLUSTAL $\mathrm{w}$ and subsequently manually adjusted. The alignment was then analysed by the COBALT multiple sequence alignment tool that finds, using RPS-BLAST, BLASTP and PHI-BLAST, a collection of pairwise constraints derived from a conserved domain database, protein motif database, and sequence similarity. Pairwise constraints are then incorporated into a progressive multiple alignment (Papadopoulos \& Agarwala, 2007). The resulting alignment exported in FASTA format was phylogenetically analysed.
\end{abstract}

The genealogy of 196 PKSs on the basis of the alignment of the KS domain was inferred by neighbour-joining and maximum-parsimony (MP) analysis using MEGA version 4 (Tamura et al., 2007). Branches of zero length were collapsed and all multiple, equally parsimonious trees were saved. The majority rule consensus bootstrap tree inferred from 1000 replicates is taken to represent the evolutionary history of the taxa analysed. The MP trees were obtained using the Close-Neighbor-Interchange algorithm with search level 3, in which the initial trees were obtained with the random addition of sequences (10 replicates). The trees are drawn to scale, with branch lengths calculated using the average pathway method, and are in the units of the number of changes over the whole sequence. All positions containing gaps and missing data were eliminated from the dataset (Complete Deletion option). In addition, a more robust approach was used to infer phylogenomic relationship among the PKSs studied by performing a randomized bootstrap maximum-likelihood analysis using RAxML software (Stamatakis et al., 2008), setting the bootstrap analysis to 1000 runs and the bootstrap random seed value to 12345 . There were 736 characters and the Dayhoff mutation data matrix was used for the analysis of the alignment. Protein IDs are consistent with the comparative Trichoderma genome analysis presented in Kubicek et al. (2011); revisions to protein IDs between Joint Genome Institute (JGI) genome versions are noted in Supplementary Table S1.

$\mathbf{K}_{\mathbf{a}} / \mathbf{K}_{\mathbf{s}}$ ratio. Tajima's D statistic (Tajima, 1989) was determined with DNASp 5.0 (Librado \& Rozas, 2009), using a sliding-window approach. The pairwise $\mathrm{K}_{\mathrm{a}} / \mathrm{K}_{\mathrm{s}}$ ratio [the ratio of the number of nonsynonymous substitutions per non-synonymous site $\left(\mathrm{K}_{\mathrm{a}}\right)$ to the number of synonymous substitutions per synonymous site $\left(K_{s}\right)$ ] was determined on the respective phylogenetic tree with the aid of the $\mathrm{K}_{\mathrm{a}} /$ $\mathrm{K}_{\mathrm{s}}$ calculation tool (http://services.cbu.uib.no/tools/kaks), using prealigned sequence datasets and MP analysis. Codon-based Fisher's test and the codon-based Z-test, implemented in MEGA 4.0 (Tamura et al., 2007), were used to directly test the hypotheses of evolutionary models.

Codon usage was estimated using the codon adaptation index (CAI), which is a measure of the relative adaptation of the gene codon usage towards the codon usage of highly expressed genes for that organism (Sharp \& Li, 1987). To estimate this index, the EmBoss (http:// emboss.bioinformatics.nl/cgi-bin/emboss) program 'cai' was used (Rice et al., 2000).

\section{RESULTS}

\section{Phylogenetic analysis and manual annotation of clusters}

T. reesei was previously shown to contain 11 PKSs (Martinez et al., 2008). This number is exceeded by T. atroviride and $T$. virens, both of which have 18 PKS-encoding genes (Kubicek et al., 2011). The organizational framework for fungal PKSs based on a phylogeny of fungal PKS KS domains is well established (Kroken et al., 2003). We have therefore analysed the position of the Trichoderma PKS proteins in the phylogenetic tree (Fig. 1). The data revealed that Trichoderma contains PKS proteins that are members of the nonreducing clades I, II and III, and of the reducing clades I, III and IV. We have divided the PKS-encoding genes into orthologous groups (Table 1) and singlets (Table 2). The $T$. reesei genome has only two singlet PKS-encoding genes, while the $T$. virens and $T$. atroviride genomes have seven and nine singlet PKS-encoding genes, respectively (Fig. 2, Table 2). There are only minor differences between our MP (Fig. 1) and maximum-likelihood analyses (Supplementary Fig. S1), the most significant being the placement of the predicted fungal 6methylsalicylic acid synthase (MSAS) PKSs.

\section{Predicted pigment genes}

The genomes of all three Trichoderma genomes encode PKS genes that group in the non-reducing fungal PKS clade I, which includes the genes associated with Fusarium graminearum aurofusarin (Frandsen et al., 2011; Kim et al., 2005; Malz et al., 2005), Fusarium fujikuroi bikaverin (Linnemannstöns et al., 2002; Wiemann et al., 2009) and Aspergillus spp. DHN melanin (Baker, 2008; Chiang et al., 2011; Jørgensen et al., 2011; Langfelder et al., 1998; Tsai et al., 1998, 2001; Watanabe et al., 1999, 2000). In addition, all three genomes encode putative multi-copper oxidases that are clustered with the PKS genes and distantly related to Aspergillus fumigatus brown $2 /$ Arp2 and $F$. graminearum gip1 pigment pathway-associated genes (Fig. 3). The third gene in the putative pigment clusters shows amino acid sequence similarity to the recently characterized protein product of $F$. graminearum aur $Z$, which has been shown to convert the compound YWA1 to nor-rubofusarin (Frandsen et al., 2011). None of the Trichoderma genomes has genes that are related to known hydroxynaphthalone (HN) reductases, which catalyse the conversion of 1,3,6,8-tetrahydroxynaphthalene to scytalone and the reduction of $1,3,8$ trihydroxynaphthalene to vermelone. It is therefore intriguing that both the T. atroviride and the T. virens genomes contain 
Table 1. Trichoderma PKS orthologous groups

\begin{tabular}{|c|c|c|}
\hline Orthologous group or singlet designation & Protein ID-percentage identity & Clade \\
\hline PKS group 1 & 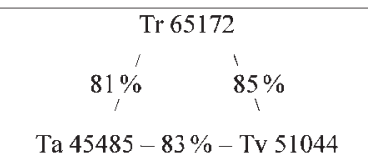 & $\begin{array}{l}\text { Reducing clade I: lovastatin/citrinin } \\
\text { diketide }\end{array}$ \\
\hline PKS group 2 & \begin{tabular}{c|c}
$\operatorname{Tr} 65891$ \\
$68 \%$ \\
$\operatorname{Ta} 51909-72 \%-\operatorname{Tv} 42255$
\end{tabular} & $\begin{array}{l}\text { Reducing clade I: lovastatin/citrinin } \\
\text { diketide }\end{array}$ \\
\hline PKS group 3 & $\begin{array}{c}\operatorname{Tr} 105804 \\
67 \% \\
\operatorname{Ta} 31567-76 \%-\operatorname{Tv} 10060\end{array}$ & Non-reducing fungal PKS clade III \\
\hline PKS group 4 & $\begin{array}{c}\operatorname{Tr} 82208 \\
73 \% \\
\text { Ta } 79-77 \%-\operatorname{Tv} 77826\end{array}$ & Non-reducing fungal PKS clade I \\
\hline PKS group 5 & $\begin{array}{cc}\operatorname{Tr} 59482 \\
80 \% & 83 \% \\
\operatorname{Ta} 34066-80 \% & -\operatorname{Tr} 53926\end{array}$ & $\begin{array}{c}\text { Reducing PKS clade III: } \\
\text { t-toxin }\end{array}$ \\
\hline PKS group 6 & $\begin{array}{c}\operatorname{Tr} 60118 \\
70 \% \\
\text { Ta } 146945-73 \%-\operatorname{Tv} 47828\end{array}$ & $\begin{array}{l}\text { Reducing PKS clade I: } \\
\text { lovastatin/citrinin diketide }\end{array}$ \\
\hline PKS group 7 & $\begin{array}{c}\operatorname{Tr} 65116 \\
82 \% \\
\operatorname{Ta} 45973-84 \%-\operatorname{Tv} 47407\end{array}$ & $\begin{array}{l}\text { Reducing PKS clade IV: } \\
\text { fumonisins }\end{array}$ \\
\hline PKS group 8 & $\begin{array}{c}\text { Tr } 81964 \\
\mid \\
75 \% \\
\mid \\
\text { Tv } 49800\end{array}$ & $\begin{array}{l}\text { Non-reducing fungal PKS clade I- } \\
\text { II }\end{array}$ \\
\hline PKS group 9 & $\begin{array}{c}\text { Tr } 106272 \\
\mid \\
77 \% \\
\mid \\
\text { Tv } 35498\end{array}$ & $\begin{array}{l}\text { Reducing clade I: lovastatin/citrinin } \\
\text { diketide }\end{array}$ \\
\hline PKS group 10 & $\begin{array}{c}\text { Ta } 83179 \\
\mid \\
77 \% \\
\mid \\
\text { Tv } 41840\end{array}$ & $\begin{array}{l}\text { Reducing PKS clade IV: } \\
\text { fumonisins }\end{array}$ \\
\hline PKS group II & $\begin{array}{c}\text { Ta } 33843 \\
\mid \\
77 \% \\
\mid \\
\text { Tv } 29151\end{array}$ & $\begin{array}{l}\text { Reducing clade I: lovastatin/citrinin } \\
\text { diketide }\end{array}$ \\
\hline
\end{tabular}

genes, not clustered with the putative pigment PKS genes, which are predicted to encode scytalone dehydratases.

\section{Evolution of the PKS genes}

In order to examine whether the Trichoderma PKSencoding genes would indeed be products of horizontal gene transfer (HGT) or be subject to other evolutionary mechanisms, we first used Tajima's D test (Tajima, 1989). To this end, we grouped the Trichoderma PKS-encoding genes according to their position in the phylogenetic tree into five datasets: (a) non-reducing PKS clades I and II; (b) non-reducing PKS clade III; (c) reducing PKS clade I and II (lovastatin-type); (d) reducing PKS clade III (fumonisintype); and (e) a small clade that occupied a basal position to the reducing PKS clades. Tajima's D was calculated with a 
Table 2. PKS singlets

\begin{tabular}{|lll|}
\hline Singlet & Protein ID & \multicolumn{1}{c|}{ Clade } \\
\hline PKS singlet 1 & Ta 79482 & Non-reducing fungal PKS clade III \\
PKS singlet 2 & Ta 32458 & Reducing PKS clade IV fumonisins \\
PKS singlet 3 & Ta 52962 & Reducing clade I: lovastatin/citrinin diketide \\
PKS singlet 4 & Ta 85006 & Reducing clade I: lovastatin/citrinin diketide \\
PKS singlet 5 & Ta 134224 & Reducing clade I: lovastatin/citrinin diketide \\
PKS singlet 6 & Ta 51503 & Reducing clade I: lovastatin/citrinin diketide \\
PKS singlet 7 & Ta 51726 & Non-reducing fungal PKS clade II-III \\
PKS singlet 8 & Ta 80219 & Non-reducing fungal PKS clade I-II \\
PKS singlet 9 & Ta 45540 & Fungal MSAS PKS \\
PKS singlet 10 & Tr 73621 & Non-reducing fungal PKS clade III \\
PKS singlet 11 & Tr 73618 & Reducing clade I: lovastatin/citrinin diketide \\
PKS singlet 12 & Tv 53518 & Reducing clade I: lovastatin/citrinin diketide \\
PKS singlet 13 & Tv 53633 & Reducing PKS clade IV: fumonisins \\
PKS singlet 14 & Tv 70876 & Reducing PKS clade IV: fumonisins \\
PKS singlet 15 & Tv 62549 & Reducing clade I: lovastatin/citrinin diketide \\
PKS singlet 16 & Tv 64883 & Reducing clade I: lovastatin/citrinin diketide \\
PKS singlet 17 & Tv 20101 & Non-reducing fungal PKS clade III \\
PKS singlet 18 & Tv 39352 & Non-reducing fungal PKS clade II-III \\
\hline
\end{tabular}

sliding-window approach over the length of the KS domainencoding portion of the gene. The data are shown in Fig. 4: Tajima's D was between 0 and -0.15 throughout in the genes in clades (a) to (d), and only the basal branch (e) showed three areas of slightly positive values. $P$ values were all $>0.05$, however, and we therefore conclude that the evolution of the PKS-encoding genes is neutral. We also used the $\mathrm{K}_{\mathrm{a}} / \mathrm{K}_{\mathrm{s}}$ ratio as an alternative means to test whether the PKS-encoding genes are under any evolutionary selection. To this end, we calculated the $\mathrm{K}_{\mathrm{a}} / \mathrm{K}_{\mathrm{s}}$ ratio for all pairwise combinations of genes. With all five groups, we

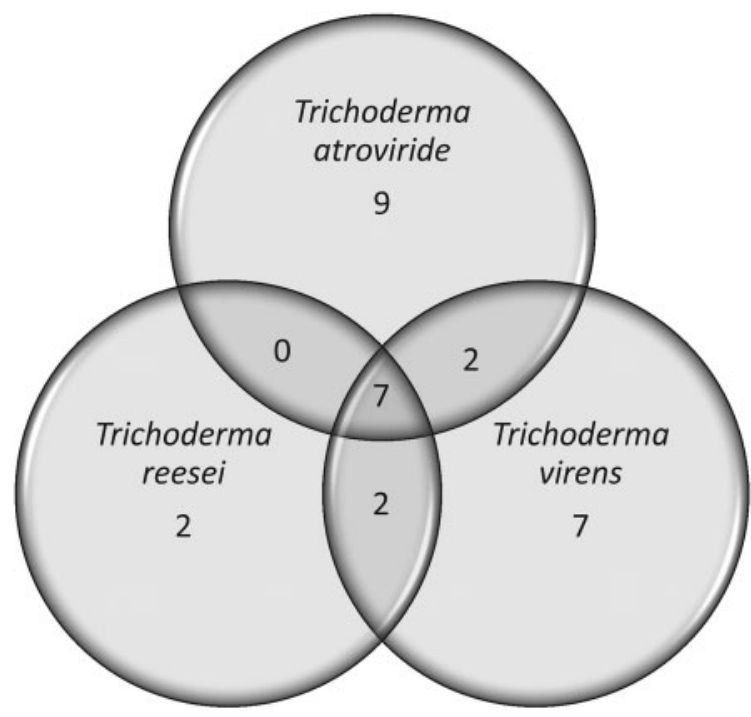

Fig. 2. Venn diagram illustrating distribution of orthologous $T$. reesei, $T$. virens and $T$. atroviride PKS-encoding genes. only obtained ratios that were significantly less than 1 , which indicates the operation of negative or purifying selection, the actual ratios varying between 0.02 and 0.6 . When the $K_{a} / K_{s}$ ratios were plotted on the nodes of the phylogenetic tree of the five PKS clades, the lowest values were observed in most (albeit not all) of the terminal clades, whereas the highest values were associated with internal nodes that represented ancient splitting events (Supplementary Figs S2-S5).

We further used the codon-based Z-test and the codonbased Fishers's exact test to compare the relative abundance of synonymous and non-synonymous substitutions that have occurred in the gene sequences. The first test did not reject the null hypothesis of purifying selection, whereas that of neutral and positive selection was rejected; in Fisher's exact test, a $p$ of 1.0 also supported purifying selection, rather than positive selection. We therefore conclude that the PKS-encoding genes of Trichoderma evolve under purifying selection.

\section{CAI}

To estimate deviations in codon usage, the CAI was calculated for all five datasets. CAI is a measure of the relative adaptiveness of the codon usage of a gene towards the codon usage of highly expressed genes for that organism: the higher the index value, the greater the codon usage bias (Sharp \& Li, 1987). CAI was previously determined for 100 orthologous and syntenic genes in $T$. reesei, $T$. virens and $T$. atroviride, and the mean value was around 0.72 (Kubicek et al., 2011). We also checked CAI for the strongly expressed fungal chitinase gene CHI18-5 (Seidl et al., 2005) and arrived at values between 0.65 and 0.8. The corresponding values for the five PKS clades of this study were between 0.65 and 0.7 (Supplementary Table S2). Therefore, there is a moderate codon usage bias in 


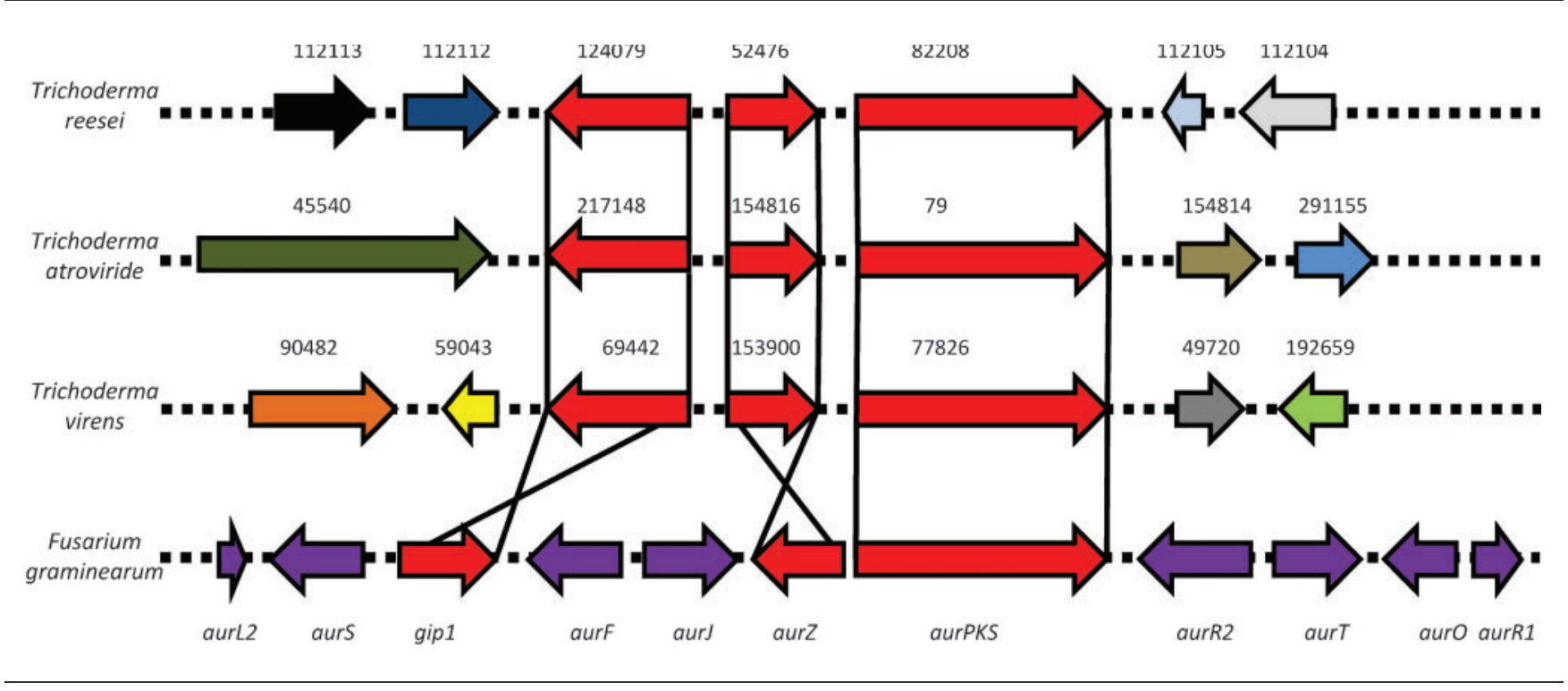

Fig. 3. Predicted pigment biosynthetic gene clusters for three Trichoderma species compared with the aurofusarin biosynthetic cluster from F. graminearum. Numbers indicate JGI protein IDs associated with the gene model and are consistant with the numbering in Kubicek et al. (2011).

the PKS-encoding genes, probably indicative of moderate levels of expression. However, the values are high enough to conclude that none of these genes was recently acquired as the result of a horizontal transfer event.

\section{DISCUSSION}

Phylogenetic analysis of protein family coding sequences is a valuable aid for gene annotation and hypothesis generation. We have performed such an analysis on PKSencoding genes from three genome-sequenced Trichoderma

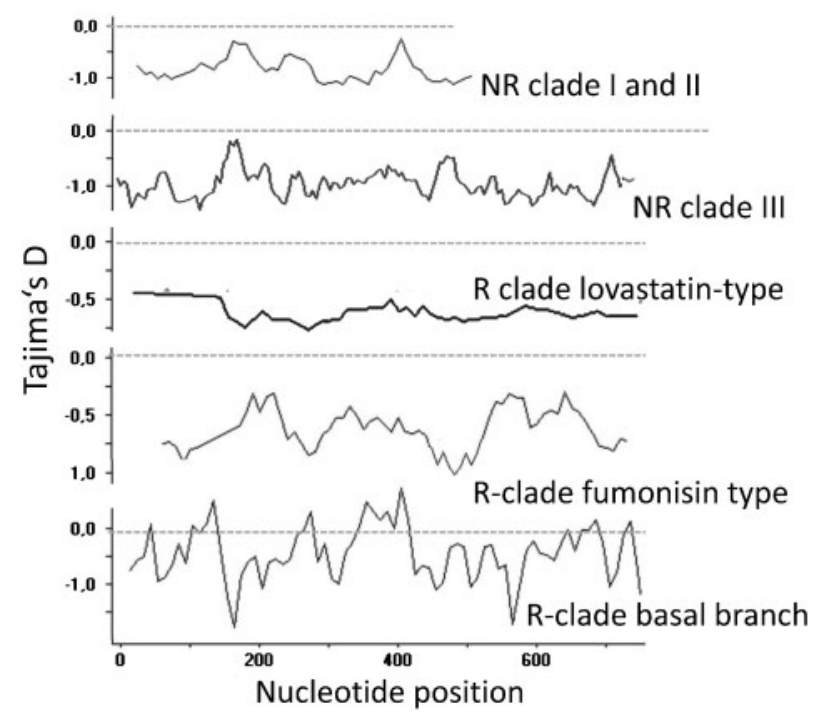

Fig. 4. Tajima's D for the KS domains of each Trichodermacontaining PKS clade plotted against nucleotide position. species and those examined by Kroken et al. (2003). We find that the majority of PKS-encoding genes (29 out of a total of 47) fall into an orthologous group. It may be that Trichoderma as a genus has a limited catalogue of PKSs and that diversity in the respective metabolites may be low or is expanded at the level of 'accessory enzymes' versus the backbone synthesizing enzyme. However, as the number of sequenced Trichoderma genomes increases, the diversity of the PKS-encoding gene family within this genus will expand as well.

Our analysis has also allowed us to predict the PKSencoding gene most likely responsible for the characteristic Trichoderma yellow-green pigment. Indeed, the value of this study and others like it is in the generation of hypotheses to be tested. Ultimately, our prediction must be validated by genetic and biochemical characterization of the Trichoderma pigment biosynthesis system. It is also interesting to note that there is synteny only at the level of the putative pigment biosynthetic cluster; the surrounding genes are not conserved. Most of the PKS-encoding genes present in $T$. reesei are also found in $T$. virens and $T$. atroviride, but about half of the genes remaining in the latter two are novel for the respective species, and similar to the case of the putative pigment cluster, form non-syntenic islands (C. P. Kubicek \& S. E. Baker, unpublished data) in the genome, suggesting transfer by recombination.

Most of the Trichoderma PKS genes occur as orthologues in all three species, implying that several nearly identical polyketides are produced by $T$. reesei, $T$. virens and $T$. atroviride. In this regard, the almost complete lack of duplicated copies was remarkable: this could be due to repeat-induced point mutation (RIP) in Trichoderma, which occurs during sexual development and alters 
nucleotides in both copies of duplicated genes and renders them nonfunctional. Evidence for the operation of RIP in Trichoderma has been presented (Kubicek et al., 2011). The operation of RIP would also be consistent with the much lower number of PKSs in $T$. reesei than in $T$. atroviride and $T$. virens, because $T$. reesei is almost always observed as a teleomorph while the other two species are frequently sampled as anamorphs. RIP may therefore also explain the - in comparison with other Pezizomycota - low number of PKS genes; indeed, only Neurospora crassa is known to have a lower number (Galagan et al., 2003), for which strong RIP is known (Selker \& Garrett, 1988; Selker et al., 1987a, b).

There is also a still-ongoing debate about whether or not HGT contributes or has contributed to the evolution of PKS genes. Modular PKS genes appear to be transferred horizontally between bacteria similarly to iterative PKS genes (Ridley et al., 2008). Kroken et al. (2003), however, demonstrated that there is little evidence for HGT with the fungal PKS genes (an exception being MSAS-encoding genes, which represent an HGT event from bacteria to fungi), and stressed the major importance of gene duplications eventually followed by gene loss. Our evolutionary analysis is consistent with the latter scenario. First, examination of the codon usage pattern showed that the codon bias is similar to that of other moderately expressed genes of Trichoderma. Further, the overall substitution ratios of the Trichoderma PKS ketoacyl synthase module revealed that it is under strong purifying selection. Similar findings have also been reported for PKS from bacteria (Zucko et al., 2011) and lichenized fungi (Muggia et al., 2008).

Our analysis lays the groundwork for future polyketide studies in Trichoderma. As more PKSs are linked to metabolite structures, the predictive value of this type of analysis will increase.

\section{ACKNOWLEDGEMENTS}

S. E. B. is funded by the DoE Office of the Biomass Program. N.M.R. is funded by an undergraduate research fellowship from Washington State University Pullman.

\section{REFERENCES}

Baker, S. E. (2008). Aspergillus genomics and DHN-melanin conidial pigmentation. In Aspergillus in the Genomic Era, pp. 73-85. Edited by J. Varga \& R. A. Samson. Wageningen, The Netherlands: Wageningen Academic Publishers.

Bushley, K. E. \& Turgeon, B. G. (2010). Phylogenomics reveals subfamilies of fungal nonribosomal peptide synthetases and their evolutionary relationships. BMC Evol Biol 10, 26.

Bushley, K. E., Ripoll, D. R. \& Turgeon, B. G. (2008). Module evolution and substrate specificity of fungal nonribosomal peptide synthetases involved in siderophore biosynthesis. BMC Evol Biol 8, 328.

Chiang, Y. M., Oakley, B. R., Keller, N. P. \& Wang, C. C. (2010). Unraveling polyketide synthesis in members of the genus Aspergillus. Appl Microbiol Biotechnol 86, 1719-1736.
Chiang, Y. M., Meyer, K. M., Praseuth, M., Baker, S. E., Bruno, K. S. \& Wang, C. C. (2011). Characterization of a polyketide synthase in Aspergillus niger whose product is a precursor for both dihydroxynaphthalene (DHN) melanin and naphtho- $\gamma$-pyrone. Fungal Genet Biol 48, 430-437.

Cox, R. J. (2007). Polyketides, proteins and genes in fungi: programmed nano-machines begin to reveal their secrets. Org Biomol Chem 5, 2010-2026.

Cramer, R. A., Jr, Stajich, J. E., Yamanaka, Y., Dietrich, F. S., Steinbach, W. J. \& Perfect, J. R. (2006). Phylogenomic analysis of non-ribosomal peptide synthetases in the genus Aspergillus. Gene 383, 24-32.

Frandsen, R. J., Schütt, C., Lund, B. W., Staerk, D., Nielsen, J., Olsson, S. \& Giese, H. (2011). Two novel classes of enzymes are required for the biosynthesis of aurofusarin in Fusarium graminearum. J Biol Chem 286, 10419-10428.

Gaffoor, I., Brown, D. W., Plattner, R., Proctor, R. H., Qi, W. \& Trail, F. (2005). Functional analysis of the polyketide synthase genes in the filamentous fungus Gibberella zeae (anamorph Fusarium graminearum). Eukaryot Cell 4, 1926-1933.

Galagan, J. E., Calvo, S. E., Borkovich, K. A., Selker, E. U., Read, N. D., Jaffe, D., FitzHugh, W., Ma, L. J., Smirnov, S. \& other authors (2003). The genome sequence of the filamentous fungus Neurospora crassa. Nature 422, 859-868.

Jørgensen, T. R., Park, J., Arentshorst, M., van Welzen, A. M., Lamers, G., Vankuyk, P. A., Damveld, R. A., van den Hondel, C. A., Nielsen, K. F. \& other authors (2011). The molecular and genetic basis of conidial pigmentation in Aspergillus niger. Fungal Genet Biol 48, 544-553.

Kim, J. E., Han, K. H., Jin, J., Kim, H., Kim, J. C., Yun, S. H. \& Lee, Y. W. (2005). Putative polyketide synthase and laccase genes for biosynthesis of aurofusarin in Gibberella zeae. Appl Environ Microbiol 71, 1701-1708.

Kroken, S., Glass, N. L., Taylor, J. W., Yoder, O. C. \& Turgeon, B. G. (2003). Phylogenomic analysis of type I polyketide synthase genes in pathogenic and saprobic ascomycetes. Proc Natl Acad Sci U S A 100, 15670-15675.

Kubicek, C. P., Herrera-Estrella, A., Seidl-Seiboth, V., Martinez, D. A., Druzhinina, I. S., Thon, M., Zeilinger, S., Casas-Flores, S., Horwitz, B. A. \& other authors (2011). Comparative genome sequence analysis underscores mycoparasitism as the ancestral life style of Trichoderma. Genome Biol 12, R40.

Langfelder, K., Jahn, B., Gehringer, H., Schmidt, A., Wanner, G. \& Brakhage, A. A. (1998). Identification of a polyketide synthase gene $(p k s P)$ of Aspergillus fumigatus involved in conidial pigment biosynthesis and virulence. Med Microbiol Immunol (Berl) 187, 79-89.

Lee, B. N., Kroken, S., Chou, D. Y., Robbertse, B., Yoder, O. C. \& Turgeon, B. G. (2005). Functional analysis of all nonribosomal peptide synthetases in Cochliobolus heterostrophus reveals a factor, NPS6, involved in virulence and resistance to oxidative stress. Eukaryot Cell 4, 545-555.

Librado, P. \& Rozas, J. (2009). DnaSP v5: a software for comprehensive analysis of DNA polymorphism data. Bioinformatics 25, 1451-1452.

Linnemannstöns, P., Schulte, J., del Mar Prado, M., Proctor, R. H., Avalos, J. \& Tudzynski, B. (2002). The polyketide synthase gene pks4 from Gibberella fujikuroi encodes a key enzyme in the biosynthesis of the red pigment bikaverin. Fungal Genet Biol 37, 134-148.

Malz, S., Grell, M. N., Thrane, C., Maier, F. J., Rosager, P., Felk, A., Albertsen, K. S., Salomon, S., Bohn, L. \& other authors (2005). Identification of a gene cluster responsible for the biosynthesis of aurofusarin in the Fusarium graminearum species complex. Fungal Genet Biol 42, 420-433. 
Martinez, D., Berka, R. M., Henrissat, B., Saloheimo, M., Arvas, M., Baker, S. E., Chapman, J., Chertkov, O., Coutinho, P. M. \& other authors (2008). Genome sequencing and analysis of the biomassdegrading fungus Trichoderma reesei (syn. Hypocrea jecorina). Nat Biotechnol 26, 553-560.

Muggia, L., Schmitt, I. \& Grube, M. (2008). Purifying selection is a prevailing motif in the evolution of ketoacyl synthase domains of polyketide synthases from lichenized fungi. Mycol Res 112, 277-288.

Papadopoulos, J. S. \& Agarwala, R. (2007). COBALT: constraint-based alignment tool for multiple protein sequences. Bioinformatics 23, 1073-1079.

Rice, P., Longden, I. \& Bleasby, A. (2000). EMBoss: the European Molecular Biology Open Software Suite. Trends Genet 16, 276-277.

Ridley, C. P., Lee, H. Y. \& Khosla, C. (2008). Evolution of polyketide synthases in bacteria. Proc Natl Acad Sci U S A 105, 4595-4600.

Schuster, A. \& Schmoll, M. (2010). Biology and biotechnology of Trichoderma. Appl Microbiol Biotechnol 87, 787-799.

Seidl, V., Huemer, B., Seiboth, B. \& Kubicek, C. P. (2005). A complete survey of Trichoderma chitinases reveals three distinct subgroups of family 18 chitinases. FEBS J 272, 5923-5939.

Selker, E. U. \& Garrett, P. W. (1988). DNA sequence duplications trigger gene inactivation in Neurospora crassa. Proc Natl Acad Sci U S A 85, 6870-6874.

Selker, E. U., Jensen, B. C. \& Richardson, G. A. (1987a). A portable signal causing faithful DNA methylation de novo in Neurospora crassa. Science $238,48-53$.

Selker, E. U., Cambareri, E. B., Jensen, B. C. \& Haack, K. R. (1987b). Rearrangement of duplicated DNA in specialized cells of Neurospora. Cell 51, 741-752.

Sharp, P. M. \& Li, W. H. (1987). The codon adaptation index-a measure of directional synonymous codon usage bias, and its potential applications. Nucleic Acids Res 15, 1281-1295.

Stamatakis, A., Hoover, P. \& Rougemont, J. (2008). A rapid bootstrap algorithm for the RAxML Web servers. Syst Biol 57, 758-771.
Tajima, F. (1989). Statistical method for testing the neutral mutation hypothesis by DNA polymorphism. Genetics 123, 585-595.

Tamura, K., Dudley, J., Nei, M. \& Kumar, S. (2007). MEGA4: Molecular Evolutionary Genetics Analysis (MEGA) software version 4.0. Mol Biol Evol 24, 1596-1599.

Tsai, H. F., Chang, Y. C., Washburn, R. G., Wheeler, M. H. \& KwonChung, K. J. (1998). The developmentally regulated alb1 gene of Aspergillus fumigatus: its role in modulation of conidial morphology and virulence. J Bacteriol 180, 3031-3038.

Tsai, H. F., Fujii, I., Watanabe, A., Wheeler, M. H., Chang, Y. C., Yasuoka, Y., Ebizuka, Y. \& Kwon-Chung, K. J. (2001). Pentaketide melanin biosynthesis in Aspergillus fumigatus requires chainlength shortening of a heptaketide precursor. J Biol Chem 276, 29292-29298.

Viterbo, A., Wiest, A., Brotman, Y., Chet, I. \& Kenerley, C. (2007). The $18 \mathrm{mer}$ peptaibols from Trichoderma virens elicit plant defence responses. Mol Plant Pathol 8, 737-746.

Watanabe, A., Fujii, I., Sankawa, U., Mayorga, M. E., Timberlake, W. E. \& Ebizuka, Y. (1999). Re-identification of Aspergillus nidulans $w A$ gene to code for a polyketide synthase of naphthopyrone. Tetrahedron Lett 40, 91-94.

Watanabe, A., Fujii, I., Tsai, H., Chang, Y. C., Kwon-Chung, K. J. \& Ebizuka, Y. (2000). Aspergillus fumigatus alb1 encodes naphthopyrone synthase when expressed in Aspergillus oryzae. FEMS Microbiol Lett 192, 39-44.

Wiemann, P., Willmann, A., Straeten, M., Kleigrewe, K., Beyer, M., Humpf, H. U. \& Tudzynski, B. (2009). Biosynthesis of the red pigment bikaverin in Fusarium fujikuroi: genes, their function and regulation. Mol Microbiol 72, 931-946.

Zucko, J., Cullum, J., Hranueli, D. \& Long, P. F. (2011). Evolutionary dynamics of modular polyketide synthases, with implications for protein design and engineering. J Antibiot (Tokyo) 64, 8992.

Edited by: B. A. Horwitz 